This item was submitted to Loughborough's Research Repository by the author.

Items in Figshare are protected by copyright, with all rights reserved, unless otherwise indicated.

\title{
Thermo-mechanical modelling of polymer encapsulated electronics
}

PLEASE CITE THE PUBLISHED VERSION

PUBLISHER

(C) IEEE

LICENCE

CC BY-NC-ND 4.0

\section{REPOSITORY RECORD}

Sarvar, Farhad, Nee-Joo Teh, David C. Whalley, David A. Hutt, and Paul J. Palmer. 2019. "Thermomechanical Modelling of Polymer Encapsulated Electronics”. figshare. https://hdl.handle.net/2134/3976. 
This item was submitted to Loughborough's Institutional Repository (https://dspace.lboro.ac.uk/) by the author and is made available under the following Creative Commons Licence conditions.

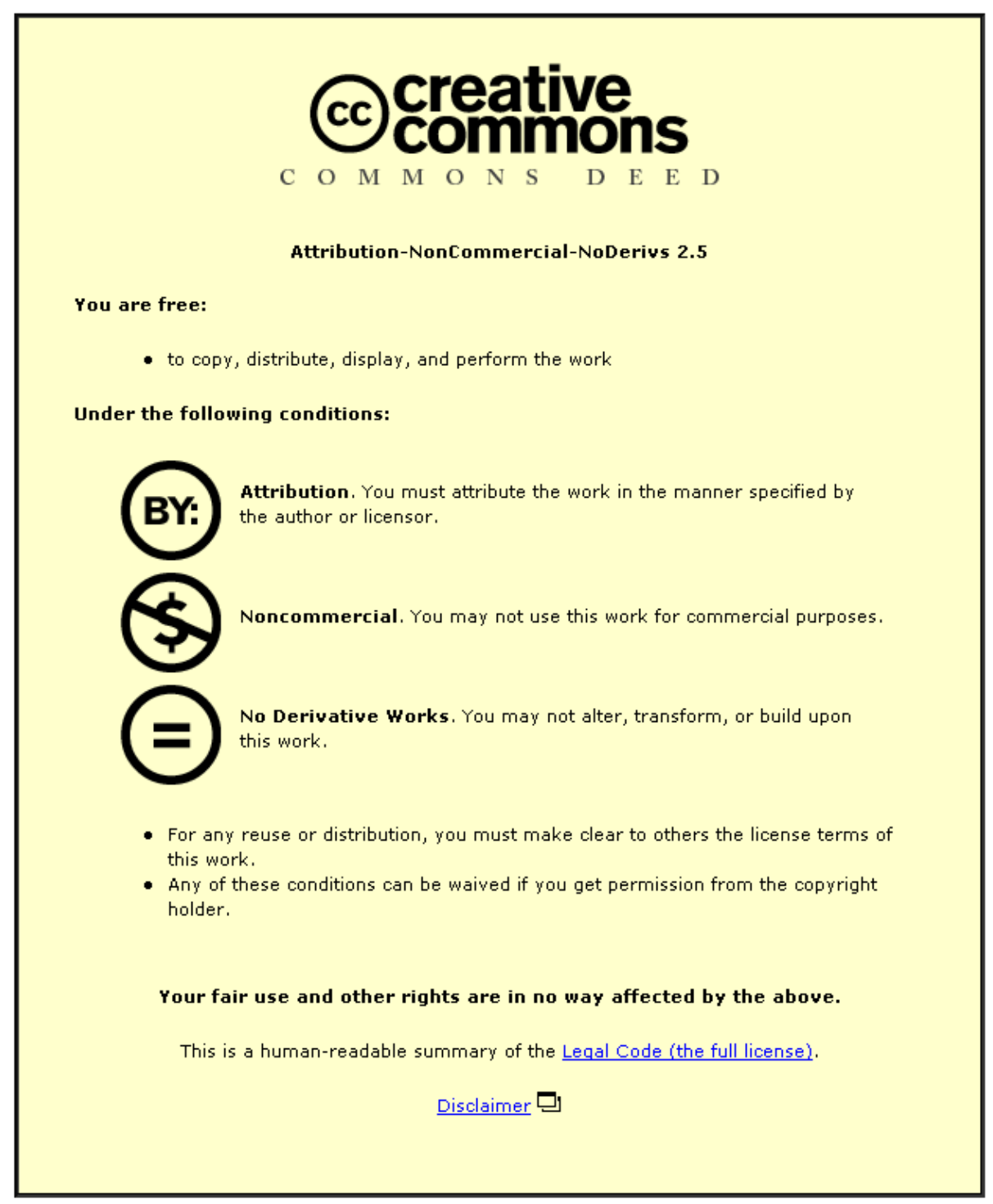

For the full text of this licence, please go to: http://creativecommons.org/licenses/by-nc-nd/2.5/ 


\title{
THERMO-MECHANICAL MODELLING OF POLYMER ENCAPSULATED ELECTRONICS
}

\author{
F. Sarvar, N. J. Teh, D. C. Whalley, D. A. Hutt and P. J. Palmer \\ Wolfson School of Mechanical and Manufacturing Engineering \\ Loughborough University, Loughborough, Leics, LE11 3TU, UK \\ Phone: +44 (0) 1509227677 \\ Email: E.Sarvar@lboro.ac.uk
}

\begin{abstract}
This paper reports on some initial results from a research project investigating a novel technology for the manufacture of recyclable polymeric modules with embedded electronic systems. The aim of this project is to develop a technology that fully encapsulates electronics for use in the demanding automotive environment. A two shot moulding technology will protect delicate electronic circuitry mounted outside of the passenger compartment from extremes of temperature, vibration and humidity. The resultant components will also be readily recyclable, making it possible to cost-effectively separate electronic components from the polymer at the end of vehicle life, allowing the recovery of high purity recyclate.
\end{abstract}

The encapsulating polymers will have low thermal conductivity, so the process of encapsulation will introduce a thermally insulating barrier around the electronics, which will impact on the dissipation of heat from the components. In addition, the thermal performance of the assembly will be further affected by the high temperature environments within which some of these electronic modules will have to operate, such as under the bonnet of a vehicle.

This paper will present the results of preliminary models developed for investigating the thermal and mechanical issues arising during the operation of such encapsulated electronics. Analytical models and finite element techniques have been employed to simulate the thermo-mechanical behaviour of overmoulded printed circuit boards.

KEY WORDS: Polymer, Encapsulation, Injection Moulding, Electronics, PCB, overmoulding, design-for-environment

\section{INTRODUCTION}

Conventional injection moulding has been used successfully to encapsulate electronic circuit boards [1]. The process was adapted, through critical parameter optimisation, [2] for use with typical glass-reinforced engineering polymers. The vital environmental factor of extracting the embedded electronics from these overmoulding plastics at the end of the operational lifecycle was however not addressed. The current work aims to address the design-for-environment issues in polymerovermoulded electronic subassemblies to allow them to conform to the requirements of the European Commission's Directive on Waste Electrical and Electronic Equipment (WEEE) [3].
Within the context of recycling of polymer encapsulated electronic modules, one of the major challenges is the clean separation of the electronic subassemblies from the overmoulding polymers. Injected at high temperatures and/or pressures, the polymer will have filled all the gaps between adjacent components and adhered to all of the component and substrate surfaces. One approach to the requirement for separation is the use of polymers that can be "programmed" (formulated) to dissolve at a pre-determined temperature (or temperature window) in the presence of an appropriate solvent. In this project water-soluble polymer blends are being used.

Such polymers are however unable to withstand aggressive automotive operating environments and a two-shot overmoulding technique is therefore being employed whereby a conventional engineering polymer is used to shield the water-soluble polymer and to provide the major mechanical functionality of the component. Potential applications are in embedded sensors and actuators.

\section{Thermo-mechanical Modelling}

The overmoulding of heat generating electronic components with inherently low thermal conductivity polymers will undoubtedly result in a reduction in the heat dissipation capability of the assembly. This issue is exacerbated by the high temperature environments within which these devices may have to survive. For power devices this could result in significant overheating and premature failure, together with thermo-mechanical deformation of the polymer material. In addition, the differences in the coefficient of thermal expansion (CTE) of the electronic components, substrate and encapsulant could cause undue stresses within the module, which may result in failure of, for example, solder joints and substrate copper tracks. Models of the thermal and mechanical issues arising during the operation of encapsulated electronics are therefore being developed. The results from these models will be used to develop a set of design guidelines that will determine the required material properties of the polymers, their maximum thickness and minimum adhesion levels. They will also be used to evaluate how thermal management structures may be integrated within the mouldings to facilitate higher power dissipations.

The work described in this paper will focus on a simple encapsulated test circuit, as shown in figure 1, which comprises of a surface mounted chip resistor, acting as a heat source, and which is soldered onto a FR4 substrate and then overmoulded with a polymer. 

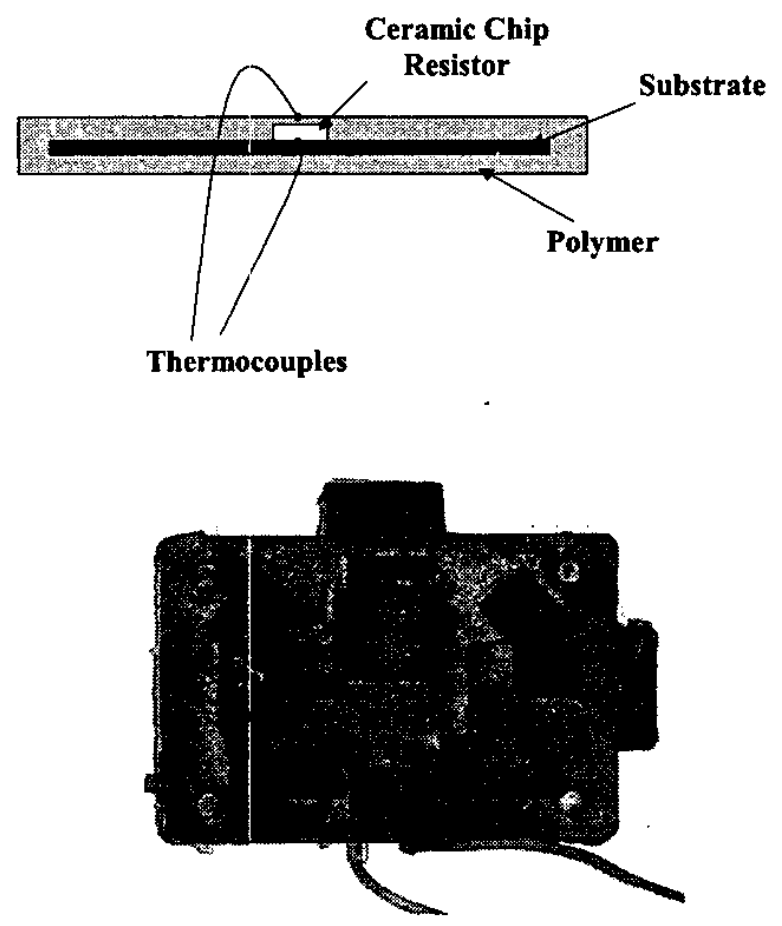

Fig. 1 Test structure

\section{MODELLING TECHNIQUES}

Several techniques were used to model the thermal performance of the device and to produce results that could be validated by comparison with experimental structures. Simple analytical one-dimensional conduction models and 2D axisymmetric finite difference (FD) were used first and then full 3D FD modelling techniques were employed for more detailed analysis.

An Excel Spreadsheet was used for the analytical model calculations. The Unigraphics Solutions EDS I-DEAS Master Series NX finite-element package was used for pre- and postprocessing of all of the FD thermal models. This was coupled with the Maya Heat Transfer Technologies' TMG (Thermal Model Generator) FD solver to simulate the heat transfer within the modules.

\section{One-dimensional Heat Conduction Model}

To begin with, a simple analytical model of the multilayer structure (resistor, substrate and polymer) was constructed to enable rapid estimation of the temperatures at various interfaces. For a prismatic slab of material the basic relationship for one-dimensional heat conduction between two faces may be stated as follows [4]:

$$
Q=\mathrm{K} A \frac{\Delta T}{L} \text { or } \Delta T=Q \times R \text { where } R=\frac{L}{K A}
$$

where $Q$ is the power dissipated (Watts), $K$ is the thermal conductivity of the material $(\mathrm{W} / \mathrm{mK}), A$ is the cross-sectional area of the slab of material through which the beat is being conducted $\left(\mathrm{m}^{2}\right), L$ is the thickness of material through which heat is conducted (m) and $\Delta T$ is the temperature difference which causes the flow of heat $\left({ }^{\circ} \mathrm{C}\right)$. Where the heat is conducted through several layers the total temperature difference is given by:

$$
\Delta T=Q \times \sum R
$$

where $\sum R$ is the sum of the thermal resistances of heat flow path, across which $\Delta T$ exists $\left({ }^{\circ} \mathrm{C} / \mathrm{W}\right)$.

In structures encountered in electronic packages the area available for conduction along the thermal path is not normally uniform. Relationships have been derived (for example [5]), which allow estimation of thermal resistances in such cases. Other methods also exist $[6,7]$ which allow the estimation of the thermal resistance from the spreading angle (as shown in figure 2) which is calculated based upon the thermal conductivities of the layers.

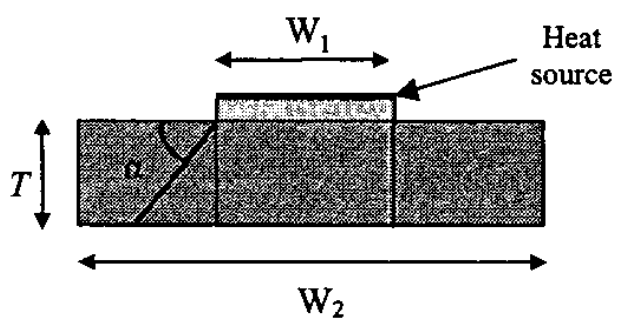

Fig. 2 Spreading angle for a rectangular heat source

The latter technique was used here to estimate the thermal resistances of the different layers namely: polymer, ceramic resistor and glass-reinforced substrate.

An Excel spreadsheet was used to perform the calculations starting from the heat source (i.e. the top surface of the chip resistor). The spreading angles were estimated for heat flow through (i) the polymer layer over the top of the resistor, (ii) the chip resistor ( 0 degree angle as heated area is assumed to cover the entire top surface of the chip), (iii) the substrate and 
(iv) the lower polymer layer. Figure 3 illustrates the spreading angles described above.

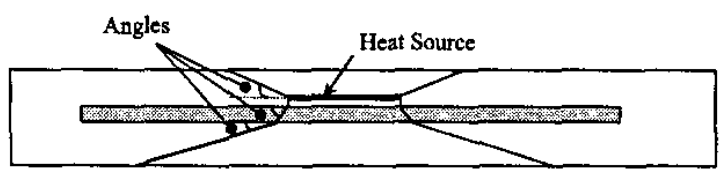

Fig. 3 Spreading angles

While analytical heat transfer models are useful for a quick assessment of designs, they are limited in their use, as heat spreading within the different layers is only roughly approximated. It is also difficult to satisfactorily model transient situations or situations with multiple heat sources. Two or three-dimensional thermal analyses are therefore required to establish more accurately the heat distribution and interaction of different heat sources within a package.

\section{Two-Dimensional Axisymmetric Finite Element Modelling}

Axisymmetric FE modelling is a commonly used technique for the modelling of structures which are symmetric about an axis of rotation and which are subjected to axisymmetric boundary conditions. Axisymmetric models have also been shown to be effective for modelling of the displacements in nonrotationally symmetric structures such as semiconductor die attach, although such models do not adequately capture the stresses at the comers of the structure [8]. They bave also been shown to adequately model the thermal resistances of such structures [9] with two orders of magnitude savings in computational effort over 3D models [10].

Axisymmetric models were therefore used for the initial evaluation of thermal performance, whilst avoiding the complexity of a full 3D model e.g. [11]. Figure 4 illustrates an axisymmetric representation of an electronic package structure consisting of a die mounted on a baseplate with a number of intermediate layers. Each layer is approximated as a cylinder having the same volume as that of the corresponding layer in the real geometry. The radius $r$ for each layer is computed from the following relationship:

$$
r=\frac{\sqrt{x \cdot y}}{\sqrt{\pi}}
$$

where $x$ and $y$ are the dimensions of the top surface of the layer.
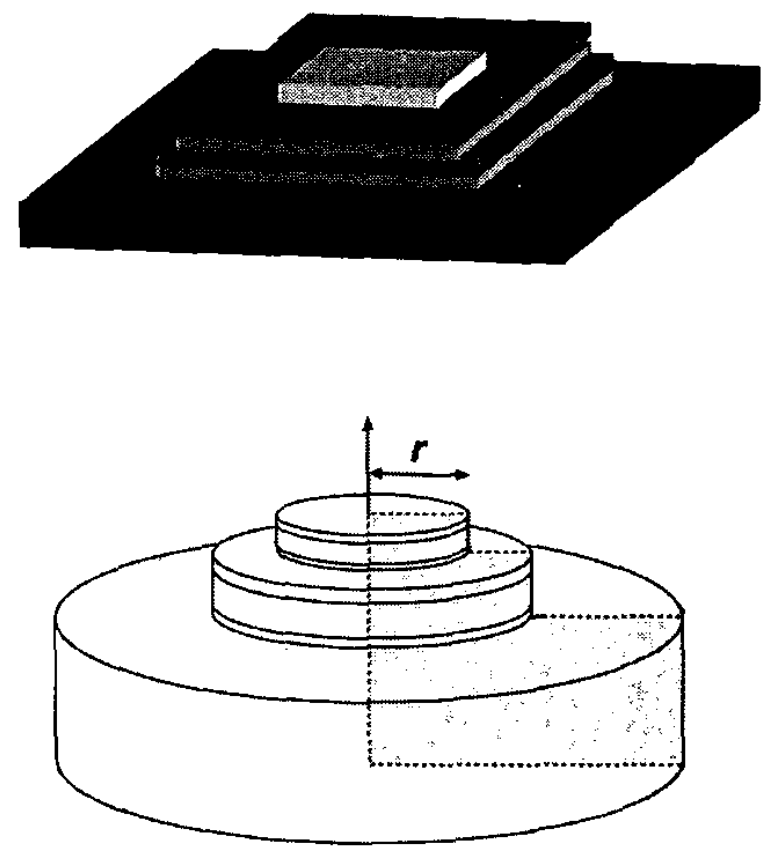

Fig. 4 Axisymmetric representation of a multilayer structure

\section{Three-dimensional FE Models}

Ultimately, the most accurate representation of a truly threedimensional (3D) structure is a full 3D FE model and only with this type of model can the detailed effects of the layout of the components within a module be established. However, such models are much more difficult to develop and, due to the far greater number of degrees of freedom within the model, much longer simulation times are required. This means that 3D models can only be created for a limited number of sets of geometry, boundary conditions and materials combinations.

\section{Thermo-mechanical Modelling}

For modelling of the thermo-mechanical phenomenon here, the results from the thermal solver are used as boundary conditions in a second, solid mechanics, analysis using the ABAQUS FE solver. The I-DEAS ABAQUS Data Translator was used to define solution parameters for ABAQUS. The translator provides bi-directional exchange of $F E$ models and simulation results with ABAQUS solvers. FE models constructed in I-DEAS can be directly written to an ABAQUS input file and ABAQUS results can be directly imported back into I-DEAS for post-processing 


\section{MODELLING RESULTS}

The models described in this section were all constructed based on the geometry of figure 1 , with the resistor centrally located on a $1.6 \mathrm{~mm}$ thick FR4 substrate, which itself was centrally positioned in a polymer overmould. The heat was assumed to be generated uniformly over the top surface of the chip resistor and, after being conducted through the different layers of the structure, was naturally convected to the surrounding ambient from all surfaces of the polymer encapsulation.

Full materials properties data for the novel polymer material in use were not available at the time of the modelling work and therefore standard values for a PBT polymer were used to provide an initial set of data. The material properties used in all of the simulations were for FR4 substrate, glass filled PBT polymer and Alumina ceramic chip resistor as shown in table 1.

\begin{tabular}{|c|c|c|c|c|}
\hline Material & $\begin{array}{c}\text { Elastic } \\
\text { Modulus } \\
(\mathrm{GPa})\end{array}$ & $\begin{array}{c}\text { Density } \\
\left(\mathrm{kg} / \mathrm{m}^{3}\right)\end{array}$ & $\begin{array}{c}\text { Thermal } \\
\text { Conductivity } \\
(\mathrm{W} / \mathrm{mK})\end{array}$ & $\begin{array}{c}\mathrm{CTE} \\
\left(\times 10^{-6} /{ }^{\circ} \mathrm{C}\right)\end{array}$ \\
\hline Alumina & 370 & 3890 & 25 & 8.2 \\
\hline FR4 & 20.6 & 1900 & 0.3 & 11.7 \\
\hline PBT & 9.97 & 1605 & 0.28 & 28.8 \\
\hline
\end{tabular}

Table 1 Material properties used in simulation

\section{One-dimensional Model}

The spreadsheet based model was used to predict steady state temperatures within an overmoulded surface mounted resistor. This was carried out for a 2512 package type with typical dimensions of $6.5 \mathrm{~mm} \times 3.25 \mathrm{~mm} \times 0.8 \mathrm{~mm}$ and which in normal applications has a power rating of $1 \mathrm{~W}$. The resistor was centrally located on the FR4 substrate $(55 \mathrm{~mm} \times 35 \mathrm{~mm} \times 1.6 \mathrm{~mm})$ and overmoulded to $60 \mathrm{~mm} \times 40 \mathrm{~mm} \times 5 \mathrm{~mm}$. The substrate was placed centrally within the moulding. Calculations were done at a number of power inputs $\left(Q_{\text {res }}\right)$ ranging from $0.25 \mathrm{~W}-1 \mathrm{~W}$. Table 2 summarises the predicted temperatures at the top of the resistor.

\begin{tabular}{|c|c|}
\hline $\begin{array}{c}Q_{\text {res }} \\
(\mathrm{W})\end{array}$ & $\begin{array}{c}\text { Peak Temperature } \\
\left({ }^{\circ} \mathrm{C}\right)\end{array}$ \\
\hline 0.25 & 40.3 \\
\hline 0.5 & 60.5 \\
\hline 1 & 101.1 \\
\hline
\end{tabular}

Table 2 Calculated temperatures for the encapsulated resistor at different power levels

\section{Two-dimensional Conduction Models}

An axisymmetric model of the single surface mounted chip resistor was then constructed as shown in figure 5 . Heat generated at the top face of the resistor was conducted through the resistor, substrate and the polymer before being dissipated to the ambient air (at $20^{\circ} \mathrm{C}$ ) by natural convection from all of the external faces. The software used standard correlations to estimate the convective coefficients. The major assumptions in these models were that the polymer was in intimate contact with the resistor/substrate assembly and that there was no gap between the resistor and substrate. It was also assumed that heat was generated uniformly over the top face of the resistor.

Figure 6 shows a predicted steady state contour profile for the structure at an input power of 0.25 Watt.

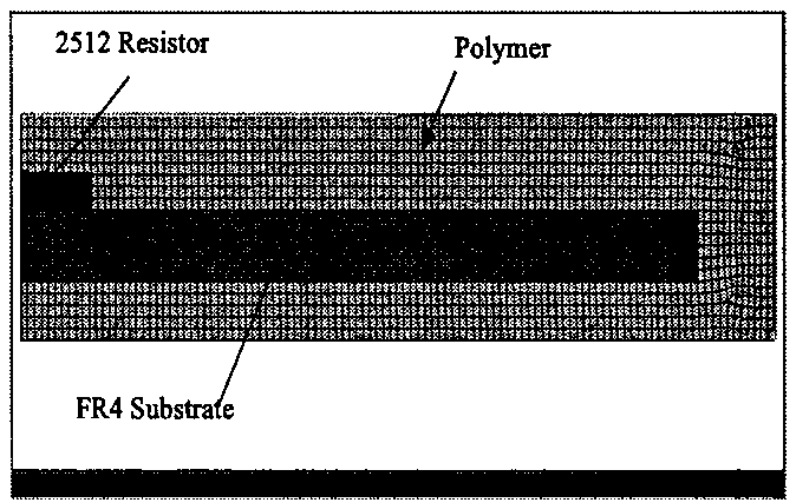

Fig. 5 Axisymmetric model of overmoulded resistor on FR4 substrate

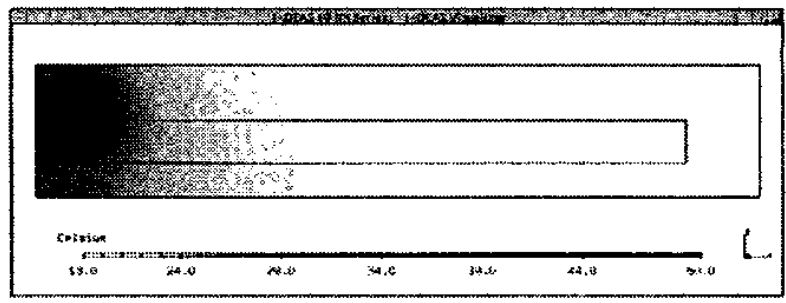

Fig. 6 A Contour map showing the simulated steady state temperatures

The simulations were carried out at different power dissipations. Figure 7 illustrates the effect of power dissipation on the temperatures recorded at two positions: the resistor/polymer interface and the polymer outer surface directly above the resistor. These initial simulations show temperature rises above ambient exceeding $110^{\circ} \mathrm{C}$ at the resistor/polymer interface for a $1 \mathrm{~W}$ input power. 


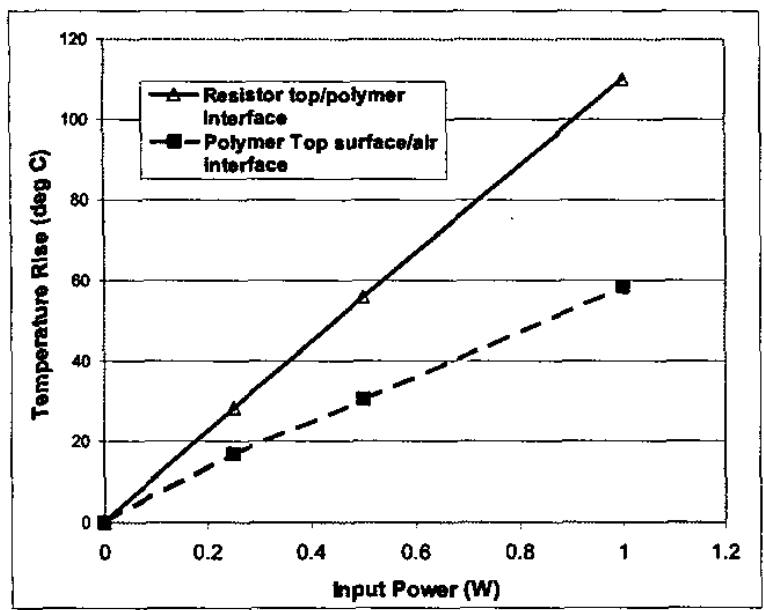

Fig. 7 Simulated temperatures for 2512 resistor axisymmetric model at different power dissipations

\section{Three-dimensional Conduction/Convection Models}

3D finite element models of the same structures were developed for analysis within the I-DEAS software package. Figure 8 illustrates four views of the model. Figure 8(a) shows the surface mounted resistor on the FR4 substrate and (b) the overmoulded resistor/substrate combination. Figures $8(\mathrm{c})$ and (d) are temperature contour maps for the top surface of the polymer and the resistor/FR4 respectively.

\section{Comparison of Different Thermal Modelling Techniques}

The results from the three different modelling approaches were compared to establish how changing the level of detail in the model affected the results. Figure 9 is a plot of the maximum temperature simulated for the top of the 2512 chip resistor at power dissipation levels ranging from 0.25 to 1 Watts. This shows good agreement between the three approaches for calculating temperatures within the overmoulded assembly.

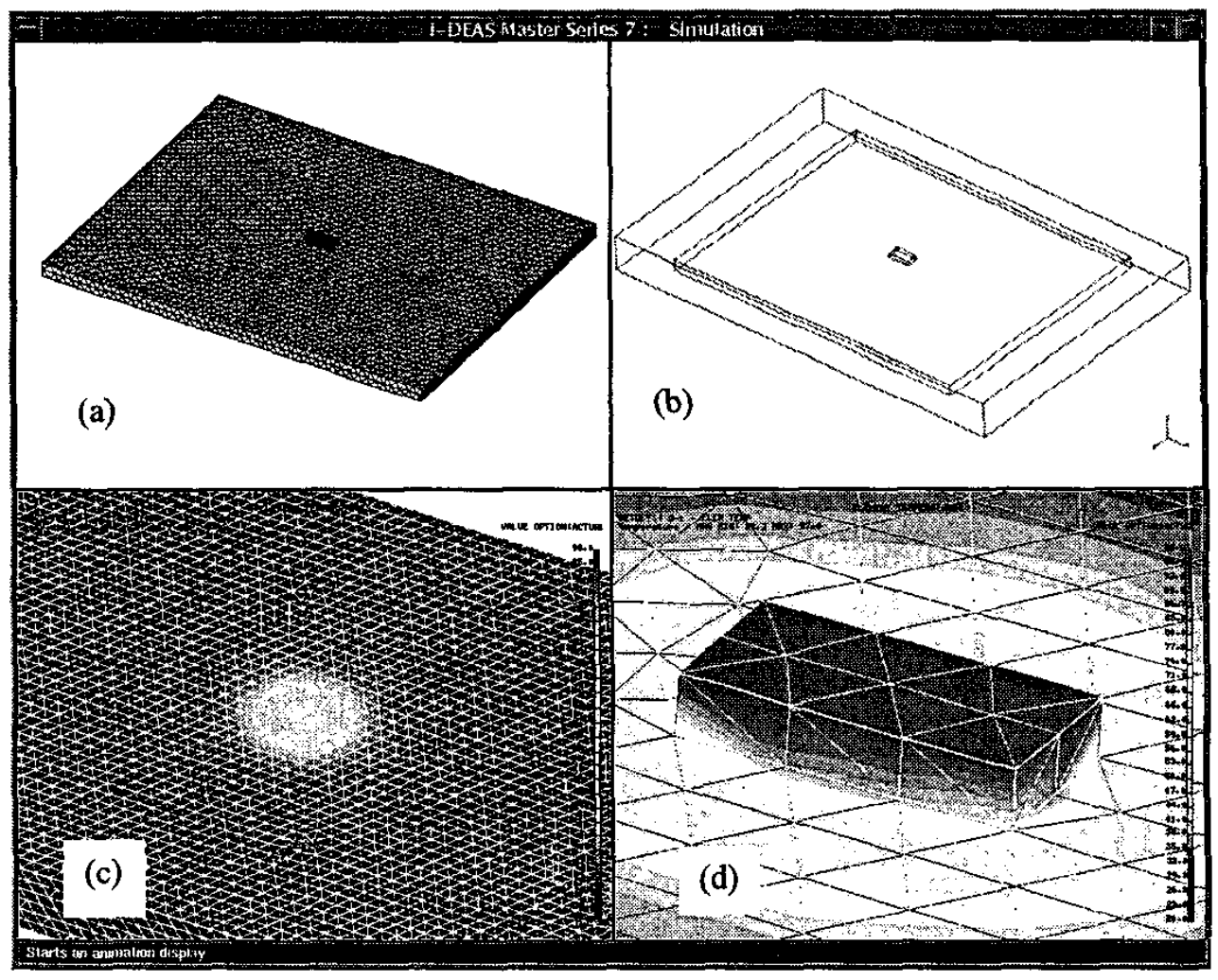

Fig 8 3D Finite element model of overmoulded resistor/substrate 


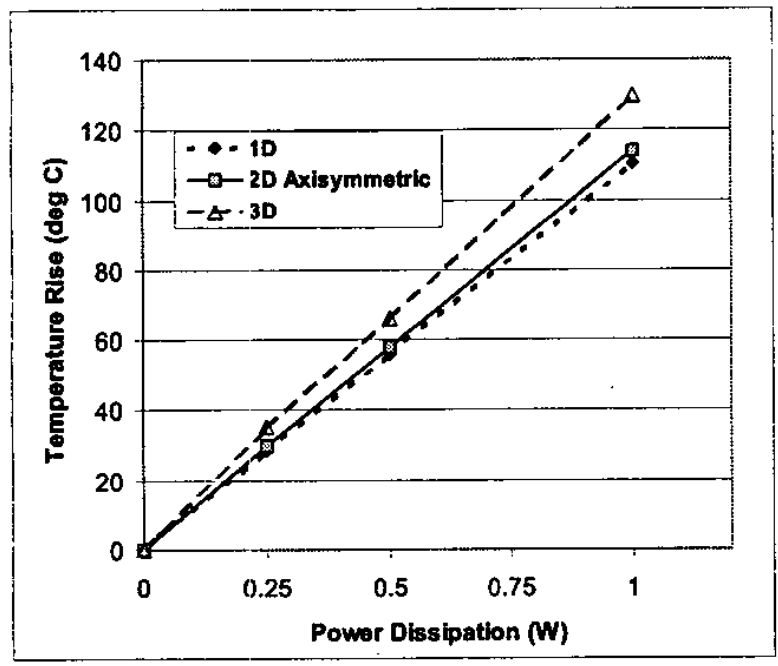

Fig. 9 Comparison of predicted temperatures for resistor top from different modelling techniques

\section{Transient Thermal Models}

In order to explore the transient thermal behaviour of the encapsulated structures, a 3D FE model similar to that described in previous sections was constructed but, in this case, with three of the same 2512 SMT resistors mounted on the PCB instead of a single resistor, at a distance of $8 \mathrm{~mm}$ from each other. In the simulation, each resistor in the assembly was subjected to an instantaneous power input of $1 \mathrm{~W}$ and the resulting thermal effects were monitored for a period of 5 minutes. The simulation was also repeated for the same board assembly but with the polymer encapsulation removed, where the heat was convected directly to the ambient air. The temperature/time results of the simulations are given in figure 10 for the centre point of the top of the resistor mounted at the middle of the board.

As expected, the results demonstrate that the assembly without the polymer encapsulation heats up at a higher rate than the overmoulded assembly, which is slowed due to the extra thermal mass introduced by the polymer. However with prolonged power input, the bare device reaches a steady state after around 100 seconds, while the polymer encapsulated board continues to heat up ultimately leading to a higher steady state temperature due to the effect of surrounding the electronics with a low thermal conductivity polymer.

\section{Thermo-mechanical Models}

For thermo-mechanical modeling, a 3D FE model was used, similar to that described for transient thermal modeling based on three 2512 SMT resistors mounted on the PCB. The simulated temperature results for a $3 \mathrm{~W}$ total input (i.e. $\mathrm{IW}$ per resistor) were applied to the FE mesh as a boundary condition. The model was then translated into an ABAQUS solver input file and subsequently solved for displacements and stresses.

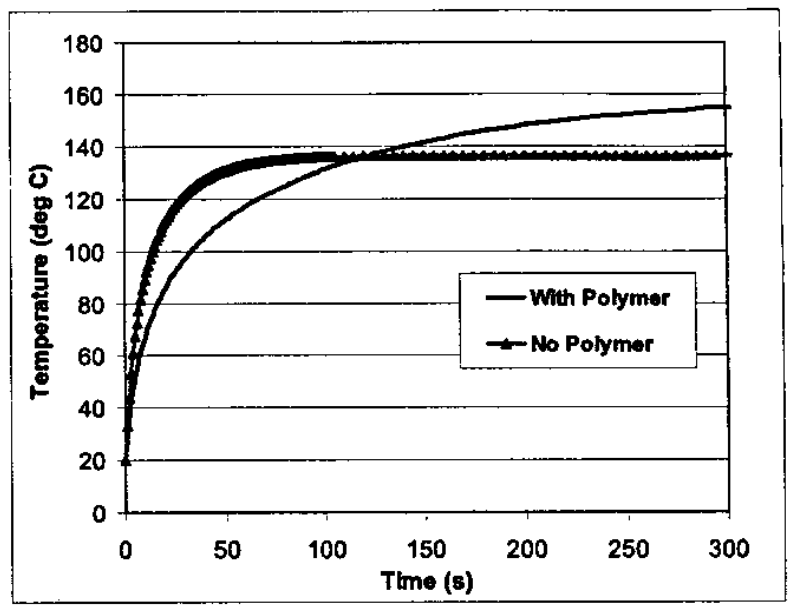

Fig. 10 Transient simulation results

The simulation assumed a temperature increase from a uniform initial ambient of $20^{\circ} \mathrm{C}$ to those from the TMG simulation. Figure 11 is a contour plot of the displacement results for the board and the three resistors showing a maximum displacement of $13 \mu \mathrm{m}$, which is well within the design specifications of the process.

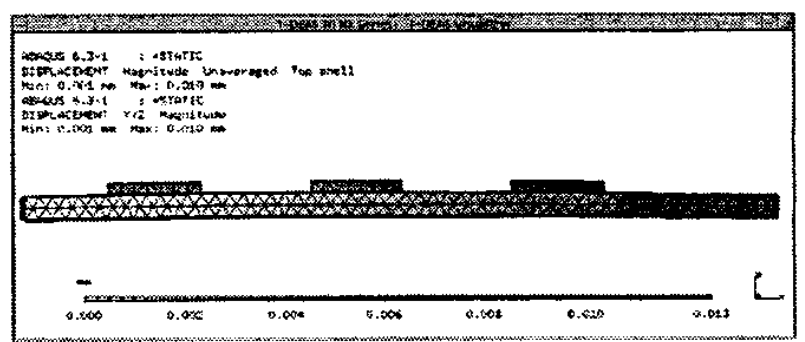

Fig. 11 Thermo-mechanical distortions for the resistors and substrate for $3 \mathrm{~W}$ input

More detailed models are currently under development, where the geometry and materials of the assembly are more accurately represented e.g. a layer of solder is included between the resistors and the substrate. Stresses on different parts of the structure will be considered in greater detail to ensure that the maximum allowable stresses for each material are not exceeded. 


\section{EXPERIMENTAL VERIFICATION OF THERMAL MODELS}

Although the modelling techniques being used have been proven in other applications, in order to establish confidence in these models for this application, it was necessary to perform comparison of the model results with experimental measurements on equivalent overmoulded structures. Initial trials were carried out on an assembly incorporating a single 1Watt rated 2512 SMT resistor as shown in Figure 1.

Thermocouples (TC) were attached to the assembly, as shown in Figure 1, (1) underneath the resistor at the resistor/substrate interface and (2) at the polymer surface directly above the resistor. For the first TC a hole was drilled through the polymer and the substrate through which a thermocouple wire was inserted and subsequently glued. The assembly was supported at the edges minimising heat conduction from the base. The resistor was powered up and left to reach steady state. The temperatures were then recorded using a datalogger. This was repeated at three different voltage/current combinations giving power dissipations of $0.25 \mathrm{~W}, 0.5 \mathrm{~W}$ and 1W. The results of these trials are presented in Table 3 along with simulated data for comparison.

\begin{tabular}{|c|c|c|c|c|c|c|}
\hline \multirow[b]{2}{*}{$\begin{array}{c}\text { TC } \\
\left({ }^{\circ} \mathrm{C}\right)\end{array}$} & \multicolumn{2}{|c|}{$0.25 \mathrm{~W}$} & \multicolumn{2}{|c|}{$0.5 \mathrm{~W}$} & \multicolumn{2}{|c|}{$1 \mathrm{~W}$} \\
\hline & 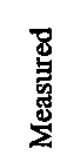 & 总 & 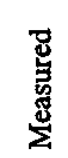 & 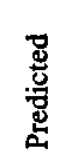 & 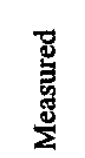 & 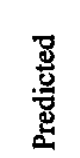 \\
\hline $\begin{array}{c}\text { Resistor } \\
\text { Bottom } \\
\left(T_{1}\right)\end{array}$ & 42.9 & 48.3 & 76 & 75.6 & 107.9 & 129.6 \\
\hline $\begin{array}{c}\text { Polymer } \\
\left(\mathrm{T}_{2}\right)\end{array}$ & 35.1 & 36.9 & 47.6 & 50.3 & 72.1 & 78.5 \\
\hline
\end{tabular}

Table 3 Temperature results from the initial experiment

These results are illustrated in Figure 12, which is a plot of temperature rise above ambient as a function of input power. Reasonable agreement is observed between the initial, experimentally measured data and the model. The discrepancies between the results are attributed to the uncertainties in the properties of the materials in the module and the inherent inaccuracies with thermocouple measurements. Materials properties measurements for the novel polymers in use are currently being carried out over the expected operating temperature range for the modules. It is envisaged that this will yield more accurate simulations.

\section{DISCUSSION AND CONCLUSIONS}

It has been shown that simple analytical models can be effectively used to carry out rapid design studies on polymer encapsulated electronics packages. The steady state results from these models compare favourably with experimental trials on prototype modules. Analytical models do not however provide a detailed representation of the effects of circuit layout on individual device temperatures and more complex 3D models have been developed in order to allow the detailed assessment of the effect of these factors on the actual device temperatures achieved. Considering the current lack of materials properties data the initial test results show good agreement between the experiment and 3D simulation for steady state situations.

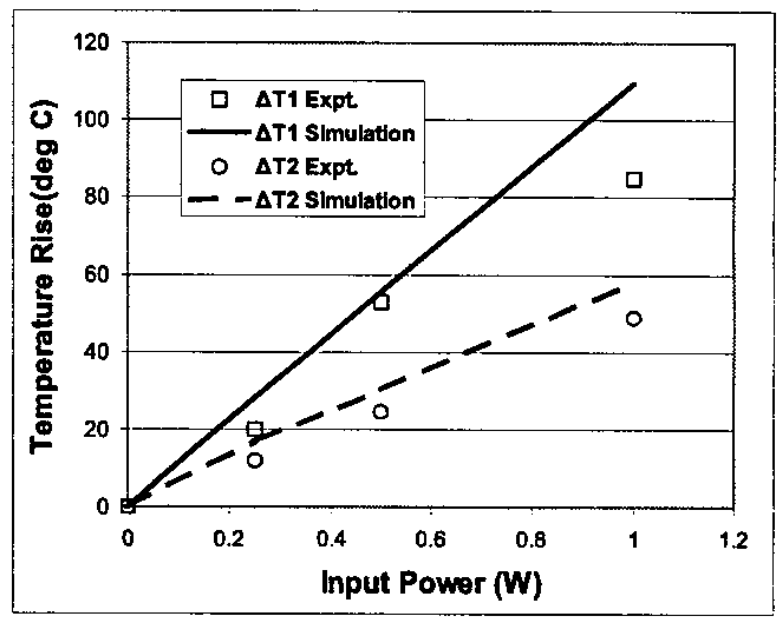

Fig. 12 Experimental and simulated temperature rise as a function of power

It is clear that any predicted result can only be as accurate as the material properties used. Since the thermo-mechanical properties for the novel polymer blend used in overmoulding the chip/substrate combinations are not currently available, the properties for glass-filled PBT polymer were used instead. This is an approximation that has given reasonable simulated results. Experimental thermo-mechanical property measurements are currently being carried out for the polymers and other materials used.

As expected, encapsulating the electronics in polymer limits the heat loss mechanism due to their inherent poor thermal conductivity. As part of this work, various methods to dissipate the heat more efficiently will be evaluated, using the thermal models. In circuits where devices/heat sources are only active for short periods of time, such as those in switching circuits, the overheating may not be of great 
importance. This has been explored in an initial transient simulation which has shown that the additional thermal mass of the polymer can reduce the temperature rise.

Initial stress analyses have shown minimal distortion in the assembly, but further models will be developed to ensure the acceptable stress for each material interface is not exceeded.

\section{A.CKNOWLEDGMENTS}

The authors acknowledge the financial support of the UK Department of Trade and Industry (DTI) under the Foresight Vehicle LINK programme and the technical support of TRW Limited, PERA International, PVAXX Research and Development Limited, Demag Hamilton Limited and Rosti.

\section{REFERENCES}

1. N.J. Teh, P.P. Conway, P.J. Palmer, S. Prosser, A. Kioul, "Embedding of Electronics within Thermoplastic Polymers using injection Moulding Technique." Proceedings from the 26th. IEMT Symposium, Santa Clara, CA. Oct 2000, pp 10-18. ISBN 0-7803-6482-1.

2. N.J. Teh, P.P. Conway, P.J. Palmer, "Statistical Optimisation of Thermoplastic Injection Moulding Process for the Encapsulation of Electronic Subassembly", Journal of Electronics Manufacturing, vol. 10, no. 3 (2000), pp 171-179. ISSN 0960-3131. Sep 2001:

3. Directive 2002/96/EC of the European Parliament and of the Council of 27 January 2003 on Waste Electrical and Electronic Equipment (WEEE).

4. D.S. Steinburg, 1991, Cooling Techniques for Electronic Equipment, Second Edition, John Wiley \& Sons, Inc., New York.

5. G. N. Ellison, 1984, Thermal Computations for Electronic Equipment, Van Nostrand Reinhold Company, New York.

6. J. E. Sergent et al, Thermal Management Handbook for Electronic Assemblies, McGraw-Hill, New York, 1998.

7. N. B. Nguyen, "Properly Implementing Thermal Spreading Will Cut Cost While Improving Device Reliability", Proc. 1996 Int. Symp. Microelectronics, Oct 1996, pp. 385-386.
8. A.O. Ogunjimi, D. C. Whalley and D. J. Williams, "A Comparison of Modelling Methods for Electronic Interconnect Structures", Proceedings of the 43rd IEEE Components, Hybrids and Manufacturing Technology Conference, IEEE, Orlando, June 1993, pp 871-876.

9. D. C. Whalley, "Thermal Modelling Techniques for Electronic Assemblies" Lucas Industries report no. LR 96 309, 1988, pp525-533.

10. Li Zhang, et al., 1999, "The Accuracy of Structural Approximations Employed in Analysis of Area Array Packages", IEEE Trans. CPMT: CPT Vol. 22, No 4.

11. F. Sarvar, D.C. Whalley, and M.K. Low, "IGBT Package Design for High Power Aircraft Electronic Systems", ASME Journal of Electronic Packaging, 123(4), December 2001, pp 338-343, ISSN 10437398. 